\title{
Open Space Mathematical Model for the Mobile Satellite L-Band Signal in Sarawak using Global Positioning System Technology
}

\author{
B. Voon Pai ${ }^{1}$, W.A.W.Z. Abidin ${ }^{1}$, H. Zen ${ }^{1}$, T. Masri ${ }^{1}$, M. Abdullah ${ }^{2}$ \\ ${ }^{1}$ Department of Electronic Engineering, Faculty of Engineering, \\ Universiti Malaysia Sarawak, \\ 94300 Kota Samarahan, Sarawak, Malaysia \\ ${ }^{2}$ Department of Electrical, Electronic \& Systems Engineering/Institute of Space Science, \\ Universiti Kebangsaan Malaysia, \\ 43600 UKM Bangi, Selangor, Malaysia \\ voon_pai@yahoo.com, wzaazlan@feng.unimas.my, zhushair@feng.unimas.my, mthelaha@feng.unimas.my, \\ mardina@eng.ukm.my
}

\begin{abstract}
The effect of ionosphere on mobile satellite (MS) L-band signal which are propagated from the transmitting satellite to the receiver over the equatorial region has attracted much interest. Sarawak which is located near the equatorial region has been selected for the purpose of this research. By means of data acquisition system using the Global Positioning System (GPS) technology, data measurement and analysis has been carried out at the Universiti Malaysia Sarawak campus in early months of 2010 . The results have been presented in the forms of received signal performance, fading characteristics and complementary cumulative distribution function of certain GPS satellites over the sky of Sarawak. A general mathematical model representing the signal strength for the open space environment in equatorial region has been developed. The availability of more satellite propagation data in different places of equatorial region will improve the MS model and quality of service perceived by MS users.
\end{abstract}

Keywords-Ionospheric effect; equatorial region; GPS; signal-to-noise ratio (SNR); MS model

\section{INTRODUCTION}

A number of efforts have been done in many parts of the world to determine factors that will affect the received signal performance of the satellite system operating in the L-band frequency $[1-3]$. It has been identified that the ionospheric effect may occur on certain part of the world especially near the equatorial region [ 4 - 7]. In Sarawak, there are very few extensive studies carried out to determine the effect of the ionosphere in received signal performance.

Sarawak is located in the east part of Malaysia (Fig. 1) in the Borneo Island $\left(1^{\circ} 33^{\prime} \mathrm{N}\right.$ of equator and $110^{\circ} 25^{\prime} \mathrm{E}$ of Greenwich). Due to its location, mobile satellite signal operating in the $1.6 \mathrm{GHz}$ frequency experience impairments such as multipath fading, ionospheric effect and shadowing effect.

There are a lot of factors that prevent extensive studies to be carried out at many other regions. One of the major obstacles is the cost of the research works. Currently, most

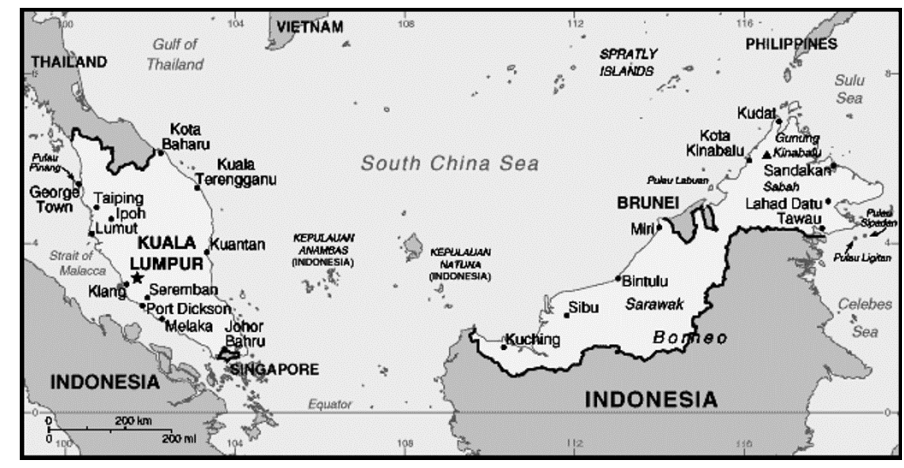

Figure 1. Sarawak location [8].

research works require expensive research equipment and rental of airborne platform such as airplane or helicopter [3]. Either method is expensive and requires significant funding. The unavailability of this funding has been one of the major hindrances in getting more data in developing and less developed countries.

In this study, data based on measurements by using a low cost and handheld GPS receiver has been examined. These data are collected continuously for 24 hours in the form of National Marine Electronic Association (NMEA) data format [9] from various GPS satellites. For analysis purposes, the raw GPS measured data in February and March 2010 which is taken in Sarawak has been used in order to analyse and identify ionospheric effect in equatorial region. In addition, the open space mathematical model for the MS signal performance in Sarawak is formulated based on March 2010 data.

\section{METHODOLOGY}

The GPS is normally used for positioning and location identification purposes [10 - 13]. Nevertheless, it is also a valuable tool for data measurements. Data acquisition system has been used to carry out measurement works by means of this GPS data. The GPS frequency of $1.575 \mathrm{GHz}$ can be used to imitate the MS signal performance. It is a method of communication between computer and GPS receiver to 